\title{
Exploring the synergistic effect of Celery and Chinese kale on Antioxidant and Anti-Pancreatic Lipase and Anti-Acetylcholinesterase activities
}

\author{
Jurairat Khongrum $^{1 *}$, Pratoomporn Yingthongchai ${ }^{1}$ and Suriya Tateing ${ }^{2}$ \\ ${ }^{1}$ Science and Technology Institute, Chiang Mai University, Thailand \\ ${ }^{2}$ Department of Plant and Soil Sciences, Faculty of Agriculture, Chiang Mai University, Thailand
}

\begin{abstract}
It has been well known that vegetables provided numerous health benefits and mixed recipe derived local vegetables have been used in traditional folklore. Therefore, this study aimed to observe the synergistic effect of the mixed water extract of Celery and Chinese kale on chemical compositions using GC-MS analysis and the biological activity including antioxidant activity and inhibited acetylcholinesterase (AChE) and suppressed pancreatic lipase by in vitro study. The GC-MS analysis of the chemical compounds showed the presence of Pyrrolidine, N,N- Dimethylaminoethanol, 2,3-Butanediol, Dimethyl trisulfide, Pentane, 3-methyl-, 3H-1,2,4-Triazol-3-one, 1,2-dihydro-, p-Cresol, 3-Butylisobenzofuran-1(3H)-one, Senkyunolide, n-Hexadecanoic acid, and Phytol. The Mixed extract significantly increased in total phenolic compound but no different in flavonoid content when compared with the extract alone. The biological activity showed that the potentials of antioxidant activity, inhibited pancreatic lipase activity and Anti-AChE activity of the mixed extract significantly increased than extract alone. The combination between celery and chinese kale extract showed high potential in antioxidant activity, inhibition of pancreatic lipase and AChE activity due to its syngenetic effect. Therefore, the combined extract is suitable for developing the functional food with positive health effects that extend beyond their nutritional value such as nutraceuticals products with mitigating hyperlipidemia and improving cognitive function.
\end{abstract}

KEYWORDS: Apium graveolens L.; Brassica oleracea L.; Antioxidant activity; Lipase; Acetylcholinesterase; GC-MS analysis

\section{INTRODUCTION}

At present, the accumulative line of scientific evidence revealed that health-promoting phytochemicals and essential minerals of fruit and vegetables significantly improved health benefits. The several reports have received considerable attention due to their potential human benefit effects including antioxidant, antiinflammatory, antimicrobial, antiallergic and anticarcinogenic capacities [1]. These effects derived from plant bioactive compound such as phenolic compounds, flavonoids, anthocyanins, carotenoids and glucosinolates [2]. In addition, increasing suggestions of health benefits may be realized from plant-derived colors possessing exceptionally high antioxidant capacity such as green pigment of chlorophylls [3]. It is well known that several green vegetables in Thailand have been long-term used as functional color-food to serves as new functional food with potential protection and treatment in various diseases.
Celery or Apium graveolens L. belongs to the family Apiaceae (Umbelliferae). It has characteristic aromatic odor because of essential oil and volatile compounds, which are largely confined to the green leaves of plant [4]. Mostly celery is composed of flavonoids and phenols including apigenin, tannins, isoquercitrin, phytic acid and graveobioside [5,6]. Celery is a medicinal plant due to its effect which contributing role on antioxidant activity $[7,8]$, antinociceptive potentials and antiinflammatory properties [9].

Chinese kale or Brassica oleracea var. alboglabra is widely distributed in southern China and Southeast Asia. Chinese kale is highly nutritious because of phytochemical constitutions, including glucosinolates, carotenoids, vitamin $\mathrm{C}$, and phenolic compounds $[10,11]$, and its abundance in health-promoting antioxidants and essential minerals [12]. The previous study reported the crucial role on health-promoting effect by the effect of cytotoxicity [13],
Quick Response Code:

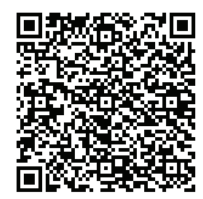

Address for correspondence: Jurairat khongrum, Science and Technology Institute, Chiang Mai University, Thailand

Received: February 03, 2021

Published: March 17, 2021

How to cite this article: Jurairat K, Pratoomporn Y, Suriya T. Exploring the synergistic effect of Celery and Chinese kale on Antioxidant and Anti-Pancreatic Lipase and Anti-Acetylcholinesterase activities. 2021- 3(2) OAJBS.ID.000264. DOI: 10.38125/OAJBS.000264 
antioxidant, anti-inflammatory, antimicrobial, antiallergic and anticarcinogenic capacities $[11,14]$. Herbal medicines, especially oriental medicine, are characterized by the use of mixtures of several herbs (multiherbs) in a single formula [15]. The effect of the multiherbs is more potential greater than used alone [16] because the therapeutic effects of these herbal products may arise from synergistic actions of herbal ingredients [17]. Therefore, this study aimed to develop a functional food product with the high potential of the combined extract between celery and chinese kale. Moreover, the chemical composition in the combined extract was evaluated by liquid chromatography-mass spectrometry (LC-MS) analysis and the biological activities to promote the health benefit effect including antioxidant, anti-pancreatic lipase and anti-AChE activities were also explored in in vitro study.

\section{MATERIALS AND METHODS}

\section{Plant Materials and Development the Recipe of the Combined Extract}

Local indigenous vegetables including Celery and Chinese kale were collected from Royal Project Foundation Farm, Chiang Mai Province during November 2019 to January 2020. The leaves and rhizomes were cleaned and cut into small pieces and dried under $40{ }^{\circ} \mathrm{C}$. Then, the ground powder was macerated with distilled water at room temperature for 72 hour and the extracts were filtered with Whatman No. 1 filter paper. The filtrate was dried by freezing dryer and the powder was kept at -20 temp. before using. In this study, we developed the recipe product by combining the water extract of Celery and Chinese kale at a ratio of $4: 1$ respectively, based on our pilot data which showed that this ratio showed the highest potential for antioxidant capacity.

\section{Determination of the Bioactive Compounds by Liquid Chromatography-mass Spectrometry (LC-MS) Analysis}

The GC-MS analysis was evaluated the bioactive compounds of the mixed extracts by Agilent Technologies GC systems with GC7890B (Agilent Technologies, Santa Clara, CA, USA) equipped with DB-5MS column (length $30 \mathrm{~m}$, diameter $0.250 \mathrm{~mm}$, film thickness $0.5 \mu \mathrm{m})$. Analysis conditions are $5 \mathrm{~min}$, at $50{ }^{\circ} \mathrm{C}, 1 \mathrm{~min}$ at $10^{\circ} \mathrm{C}$ for column temperature, $240^{\circ} \mathrm{C}$ for injector temperature, helium is the carrier gas and split ratio is 5:4. The sample $(1 \mu \mathrm{l})$ is evaporated in a split less injector at $300^{\circ} \mathrm{C}$. Run time is $53 \mathrm{~min}$. The compounds are identified by gas chromatography coupled with mass spectrometry. The structure of the compounds of the extract are ascertained by the interpretation of mass spectrum of GC-MS using the database of National Institute Standard and Technology (NIST). The mass spectrum of the unknown component is compared with the spectrum of the known components stored in the NIST library [18].

\section{Determination of the Total Phenolic and Flavonoid Contents}

The total phenolic content of the combined extract was determined by the Folin-Ciocalteu method [19]. In brief, an aliquot of $20 \mu \mathrm{l}$ of extract and gallic acid was added into test-tube containing $1.58 \mathrm{ml}$ of distilled water and $1.0 \mathrm{ml}$ of Folin-Ciocalteu phenol reagent which dissolved in 1 volume of Folin-Ciocalteu phenol (Sigma, MO, USA) with 2 volumes of distilled water. After incubating for $8 \mathrm{~min}, 0.3 \mathrm{ml}$ of $20 \% \mathrm{Na} 2 \mathrm{CO} 3$ (w/v in distilled water) was added. Then, it was incubated for $2 \mathrm{hr}$ at room temperature in dark room. Absorbance was measured at $765 \mathrm{~nm}$ with a Spectronic ${ }^{\mathrm{TM}}$ GENESYS $^{\mathrm{TM}}$ 20 spectrophotometer (Thermo electron corporation, IL, USA). The total phenolic content was expressed in $\mu \mathrm{g}$ of GAE/mg extract. Total flavonoid contents were estimated according to the aluminum chloride method [20]. Briefly, $0.5 \mathrm{ml}$ of the combined extract and quercetin were mixed with $1.5 \mathrm{ml}$ of $50 \%$ alcohol, $0.1 \mathrm{ml}$ of $10 \%$ $\mathrm{AlCl} 3,0.1 \mathrm{ml}$ of $1 \mathrm{M}$ potassium acetate and $2.8 \mathrm{ml}$ of distilled water into a test-tube. The test-tube were vortexed for $10 \mathrm{~s}$ and incubated at room temperature for $5 \mathrm{~min}$. The absorbance was measured at $415 \mathrm{~nm}$ using a Spectronic ${ }^{\mathrm{TM}}$ GENESYS $^{\mathrm{TM}} 20$ spectrophotometer (Thermo electron corporation, IL, USA). The flavonoid content was expressed in $\mu \mathrm{g}$ of quercetin/mg extract.

\section{Determination of Antioxidant Activity}

Ferric Reducing Antioxidant Power (FRAP): Ferric reducing antioxidant power assay (FRAP) was evaluated as described earlier [21]. Briefly, the FRAP reagent was prepared by $25 \mathrm{ml}$ of $300 \mathrm{mM}$ acetate buffer $\mathrm{pH} 3.6,2.5 \mathrm{ml}$ of $10 \mathrm{mM}$ tripyridyltriazine (TPTZ) solution in $40 \mathrm{mM}$ hydrochloric acid $(\mathrm{HCl})$, and $2.5 \mathrm{ml}$ of $20 \mathrm{mM}$ FeCl3 6 H2O solution. An aliquot of $50 \mu$ l of the mixed extract at different concentration was mixed with $1450 \mu \mathrm{L}$ of the FRAP reagent and $100 \mu \mathrm{l}$ of distilled water. They were incubated at $37{ }^{\circ} \mathrm{C}$ for 10 minutes in water bath. The absorbance of reaction was measured at $593 \mathrm{~nm}$ by a Spectronic ${ }^{\mathrm{TM}}$ GENESYS $^{\mathrm{TM}} 20$ spectrophotometer (Thermo electron corporation, IL, USA). The results were expressed $\mathrm{IC}_{50}$ value of the sample.

2,20-azino-bis-(3-ethylbenzothiazoline-6-sulphonic acid) diammonium salt (ABTS): Free radical scavenging activity of the extract was determined by ABTS radical cation decolorization assay [22]. ABTS + cation radical was produced by the reaction between $7 \mathrm{mM}$ ABTS in water and $2.45 \mathrm{mM}$ potassium sulfate (1:1), stored in the dark at room temperature for 12-16h before use. ABTS-+ solution was then diluted with methanol to obtain an absorbance at $734 \mathrm{~nm}^{\mathrm{m}}$ using a Spectronic ${ }^{\mathrm{TM}}$ GENESYS $^{\mathrm{TM}} 20$ spectrophotometer (Thermo electron corporation, IL, USA). After an added $5 \mu \mathrm{l}$ of combined extract to $3.995 \mathrm{ml}$ of diluted ABTS + solution, the absorbance was measured at $30 \mathrm{~min}$ after the initial mixing. The results were expressed $\mathrm{IC}_{50}$ value of the sample.

\section{Determination of Acetylcholinesterase (AChE) Inhibition}

The evaluation of anti-AChEactivity in the extractwas performed with the colorimetric method utilizing acetylthiocholine iodide (ATCI) as a substrate [23]. The rate of production of thiocholine is determined by the continuous reaction of 5, 5-dithiobis-2nitrobenzoate (DTNB) ion to produce the yellow anion of 5-thio2-nitro-benzoic acid. In brief, $25 \mu \mathrm{l}$ of $15 \mathrm{mM}$ ATCI, $75 \mu \mathrm{l}$ of $3 \mathrm{mM}$ DTNB and $50 \mu \mathrm{l}$ of $50 \mathrm{mMTris}-\mathrm{HCl}, \mathrm{pH} 8.0$, containing $0.1 \%$ ovine serum albumin (BSA) and $25 \mu$ lo the tested phytochemicals in the combined extract were added in to the 96 well plates, and the absorbance was measured at $405 \mathrm{~nm}$ after 5 minutes of incubation at room temperature.

Then, $25 \mu \mathrm{l}$ of $0.22 \mathrm{U} / \mathrm{mL}$ of AChE (Sigma-Aldrich Corporation, St. Louis, MO, USA) was added, the absorbance was measured again after 5 minutes of incubation at room temperature. Percentage of inhibition was calculated by comparing the rate of enzymatic hydrolysis of ATCI for the samples to that of the blank $(50 \%$ aqueous methanol in buffer). Galanthamine (1-32mM) supplied by Sigma-Aldrich was used as a reference standard.

\section{Determination of Pancreatic Lipase Inhibition}

Pancreatic lipase inhibitory activity was determined by slightly modified titrimetric method [24]. In brief, porcine pancreatic lipase enzyme solution was immediately prepared at concentration $5 \mathrm{mg} / \mathrm{ml}$ in $0.1 \mathrm{M}$ sodium phosphate buffer, $\mathrm{pH}$ 8.0. The substrate 
was prepared by $4.5 \mathrm{mg}$ of P-Nitrophenylbutyrate (PNPB) with dissolved in $200 \mu \mathrm{l}$ of $\mathrm{N}, \mathrm{N}$-dimethyl formamide and final volume was made up by $10 \mathrm{ml}$ of $0.1 \mathrm{M}$ sodium phosphate buffer, $\mathrm{pH} 8.0$. The reaction solution was mixed by $10 \mu \mathrm{l}$ of pancreatic lipase, $150 \mu \mathrm{l}$ of p-nitrophenyl palmitate solution and $40 \mu \mathrm{l}$ of $0.1 \mathrm{M}$ sodium phosphate buffer. Then, $25 \mu \mathrm{l}$ of test solution and standard was incubated with $50 \mu \mathrm{l}$ of enzyme solution for 30 minutes at $37^{\circ} \mathrm{C}$. The inhibition of Lipase activity was determined by $400 \mathrm{~nm}$ of the absorbance using a microplate reader.

\section{STATISTICAL ANALYSIS}

Data are presented as the means \pm S.E.M. and were analyzed statistically using one-way ANOVA followed by a post hoc (LSD) test. The results were considered to be statistically significant at a $p$-value $<0.05$.

\section{RESULTS}

The Bioactive Chemical Compounds in the Combined Extract by GC-MS Study

Mass Spectrometer (GC-MS) is a important tool to evaluate potential to supply the definitive, qualitative and quantitative information on molecules based on their structural compositions.

In this, interpretation of mass spectrum of GC-MS was done using database of National Institute Standard and Technology (NIST). The mass spectrum of unknown component was compared with the spectrum of the known component stored in the NIST library and major components were identified by with authentic standards and by with recorded from computerized libraries.

The GC-MS spectrum confirmed the presence of various components with different retention times as illustrated in Figure 1. These mass spectra are fingerprint of that compound which can be identified from the data library. The compound name, probability, and biological activity of the combined extract were shown in the Table 1. The major compounds were Pyrrolidine, N,N- Dimethylaminoethanol, 2,3-Butanediol, Dimethyl trisulfide, Pentane, 3-methyl-, 3H-1,2,4-Triazol-3-one, 1,2-dihydro-, p-Cresol, 3-Butylisobenzofuran-1(3H)-one, Senkyunolide, n-Hexadecanoic acid, and Phytol.

The results of GC-MS study specify that the water extract of the combined plants contains various bioactive compounds. Therefore, these contribute as medicinal bioactive with promoting health benefit.

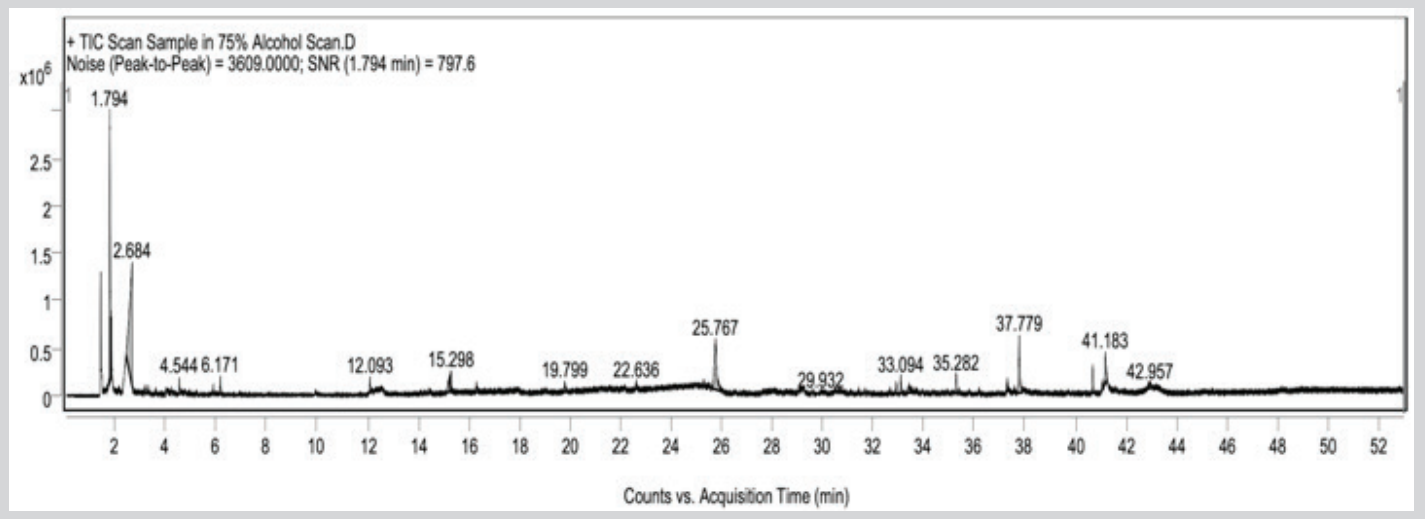

Figure 1: GC-MS analysis of the combined extract.

Table 1: The chemical composition of the combined extract exploring by GC-MS analysis.

\begin{tabular}{|c|c|c|c|c|}
\hline Name of the Compound & Retention Time & Molecular Formula & Probability & Biological Activity \\
\hline Pyrrolidine & 4.028 & C4 H9 N & 82.75 & Antioxidant \\
\hline N,N-Dimethylaminoethanol & 4.544 & C4 H11 No & 85.81 & $\begin{array}{c}\text { Phytohormone and } \\
\text { Antioxidant responses }\end{array}$ \\
\hline 2,3-Butanediol & 6.171 & C4 H10 02 & 84.28 & $\begin{array}{c}\text { Antioxidant and } \\
\text { Hepatoprotective effects }\end{array}$ \\
\hline Dimethyl trisulfide & 12.094 & C2 H6S3 & 93.33 & Antioxidant and \\
\hline Antimicrobial
\end{tabular}


The Total Phenolic and Flavonoid Contents of the Combined Extract

The phenolic and flavonoid contents in the extract of Celery and Chinese kale and the combined extract were shown in the Table 2. The results showed that total phenolic and flavonoid content of Celery extract was $111.60 \pm 2.05 \mu \mathrm{gGAE} / \mathrm{mg}$ extract and $19.04 \pm 0.59 \mu \mathrm{g}$ quercetin/mg extract, respectively and Chinese kale extract was $135.35 \pm 4.27 \mu \mathrm{gGAE} / \mathrm{mg}$ extract and $18.92 \pm 0.47 \mu \mathrm{g}$ quercetin/mg extract, respectively. The combined extract expressed at $162.37 \pm 0.88 \mu \mathrm{gGAE} / \mathrm{mg}$ extract and $20.45 \pm 0.73 \mu \mathrm{g}$ quercetin $/ \mathrm{mg}$ extract, respectively.

Interestingly, The combined extract significantly increased the total phenolic compound than celery extract $(p<0.05)$ but no difference of Chinese kale. However, the flavonoid content of the combined extract showed no significant changes when compared to extract alone.

Table 2: The total phenolic and Flavonoid contents in Celery extract, Chinese kale and combined extract.

\begin{tabular}{|c|c|c|}
\hline Extract & Total Phenolic (g GAE/mg extract) & Flavonoid (g quercetin/mg extract) \\
\hline Celery & $111.60 \pm 2.05$ & $19.04 \pm 0.59$ \\
\hline Chinese kale & $135.35 \pm 4.27$ & $18.92 \pm 0.47$ \\
\hline Combined extract & $162.37 \pm 0.88^{*}$ & $20.45 \pm 0.73$ \\
\hline
\end{tabular}

Note: Data expressed as Mean \pm S.D. $(\mathrm{N}=4)$

GAE: Gallic acid equivalent

$*, * *, * * *: p<0.05,0.01,0.001$; compared to Celery

\#,\#\#,\#\#\#: $p<0.05,0.01,0.001$;compared to Chinese kale

\section{The Effect on Antioxidant Activities}

This study determined antioxidant activity by colorimetric tests using spectrophotometric techniques. In general, spectrophotometric techniques are simple, rapid and not expensive, which probably explains their widespread use in antioxidant screening. In addition, since this techniques rely on the reaction of a radical, radical cation or complex with an antioxidant molecule, the most common methods for the in vitro determination of antioxidant capacity employed ABTS and FRAP assay. The results as showed in Table 3 showed that IC $_{50}$ values for FRAP and ABTS assay of celery extract were $2.335 \pm 0.02 \mathrm{mg} / \mathrm{ml}$ and $1.128 \pm 0.031 \mathrm{mg} /$ $\mathrm{ml}$, respectively and Chinese kale extract were $4.007 \pm 0.04$ and $16.951 \pm 0.14 \mathrm{mg} / \mathrm{ml}$, respectively.

Moreover, the combined extract showed the $\mathrm{IC}_{50}$ values of FRAP and ABTS assay at $1.591 \pm 0.08$ and $0.212 \pm 0.06 \mathrm{mg} / \mathrm{ml}$, respectively. Interestingly, The $\mathrm{IC}_{50}$ values of ABTS assay of the combined extract showed significantly lower than the extract alone $(p<0.05$ compared to celery and $p<0.05$ chinese kale). However, the IC $_{50}$ values of FRAP showed no significant changes when compared to extract alone.

Table 3: IC50 values of Antioxidant activity including FRAP and ABTS of Celery extract, Chinese kale extract and combined extract.

\begin{tabular}{|c|c|c|}
\hline Extract & IC $_{\mathbf{5 0}}$ FRAP $(\mathbf{m g} / \mathbf{m l})$ & IC $_{\mathbf{5 0}} \mathbf{A B T S}$ (mg/ $\left.\mathbf{m l}\right)$ \\
\hline Celery & $2.335 \pm 0.002$ & $0.357 \pm 0.01$ \\
\hline Chinese kale & $4.007 \pm 0.002$ & $16.951 \pm 0.14$ \\
\hline Combined extract & $1.591 \pm 0.08$ & $0.212 \pm 0.06^{*} \#$ \\
\hline
\end{tabular}

Note: Data expressed as Mean \pm S.D. $(\mathrm{N}=4)$

IC50: concentration is inhibited by $50 \%$

FRAP: Ferric Reducing Antioxidant Power

ABTS: 2,20-azino-bis-(3-ethylbenzothiazoline-6-sulphonic acid) diammonium salt

$*, * *, * * *: p<0.05,0.01,0.001 ;$ compared to celery

\#,\#\#,\#\#\#:p<0.05,0.01,0.001;compared to Chinese kale

\section{The Effect on Inhibition of Acetylcholinesterase Activity and Lipase Activity}

The results were shown in the Table 4 . The inhibition of lipase and AChE activity was expressed in $\mathrm{IC}_{50}$ value. The $\mathrm{IC}_{50}$ values for inhibition of lipase activity of the Celery extract, Chinese kale and combined extract were $0.079 \pm 0.007 \mathrm{mg} / \mathrm{ml}, 1.01 \pm 0.06 \mathrm{mg} / \mathrm{ml}$ and $0.048 \pm 0.002 \mathrm{mg} / \mathrm{ml}$, respectively. In addition, the $\mathrm{IC}_{50}$ values for inhibition of AChE activity of the Celery extract, Chinese kale and combined extract were $1.35 \pm 0.06 \mathrm{mg} / \mathrm{ml}, 1.35 \pm 0.06 \mathrm{mg} / \mathrm{ml}$ and $0.020 \pm 0.004 \mathrm{mg} / \mathrm{ml}$, respectively.Interestingly, the effect of the combined extract showed significanty higher mitigating AChE activity than extract alone $(p<0.01$ compared to celery and $p<0.01$ chinese kale) but no changes in the pancreatic lipase inhibition.

\section{DISCUSSION}

To date, numerous lines of evidence have demonstrated that the imbalance of oxidative stress homeostasis gives rise to the enhanced oxidative stress which plays the crucial role on metabolic syndrome related cognitive disorders $[25,26]$. Therefore many reports have demonstrated that the local indigenous vegetables which possessing antioxidant activity are reported to possess antimetabolic syndrome and enhancing cognitive function [27].

All data obtained from in vitro study of this study indicated that combination of Celery extract and Chinese kale extract showed higher potential than the extract alone. According to traditional medicine, the polyherbal formulation or multiherb have been longterm used to provide more benefits in the management of various 
ailments [28,29]. This was also in agreement with the present results which clearly demonstrated that the combined extract of Celery and Chinese kale provided optimum benefit concerning about antioxidant activities and capacity of the inhibited lipase and AChE activity more than extract alone. These effects may be occurred by the synergistic effect when chemical substances or biological structures interact resulting in an overall effect and multiple components in the combined extract offer great potential for synergistic actions that increasing bioactive activities. In recent years, it has become evident that synergistic effects of herbal combinations can be achieved by acting on multiple targets and improving bioavailability in crude extracts [30].

Table 4: IC50 values of inhibition of lipase and AChE activity in Celery extract, Chinese kale extract and combined extract.

\begin{tabular}{|c|c|c|}
\hline Extract & $\begin{array}{c}\mathbf{I C}_{\mathbf{5 0}} \text { of Inhibition of lipase activity (mg/ } \\
\mathbf{~ m l )}\end{array}$ & $\begin{array}{c}\mathbf{I C}_{\mathbf{5 0}} \text { of Inhibition of AChE activity (mg/ } \\
\text { ml) }\end{array}$ \\
\hline Celery & $0.079 \pm 0.007$ & $1.35 \pm 0.06$ \\
\hline Chinese kale extract & $1.01 \pm 0.06$ & $1.51 \pm 0.02$ \\
\hline Combined extract & $0.048 \pm 0.002$ & $0.020 \pm 0.004^{* * \# \#}$ \\
\hline
\end{tabular}

Note: Data expressed as MeantS.D. $(\mathrm{N}=4)$

IC50: concentration is inhibited by $50 \%$

$*, * * * * *: p<0.05,0.01,0.001 ;$ compared to celery
$\#, \# \#, \# \# \#: p<0.05,0.01,0.001 ;$ compared to Chinese kale

In addition, the dietary polyphenols have been shown to significantly alleviate several manifestations of metabolic syndrome $[31,32]$. Especially, phenolic compounds have some potential efficacy for preventing obesity by inhibiting the activity of enzymes related to fat metabolism as pancreatic lipase, lipoprotein lipase and glycerophosphate dehydrogenase [33,34]. Moreover, various phenolic acids and flavonoid derived plant have potential on lowering AChE activity [35]. According to the results, the combined extract presented Phytol, a bioactive compound, which is a member of the group of branched-chain unsaturated alcohols [36]. Phytol is the product of chlorophyll metabolism in plants and able to reduce the production of free radicals leading to its antioxidant properties [37]. Moreover, 3-n-Butylphthalide (NBP) or 3-butylisobenzofuran$1(3 \mathrm{H})$-one was found in the combined extract. It was reported that it showed important role on potent neuroprotective effect. Peng et al. found that L-3-n-butylphthalide (L-NBP) attenuated learning and memory deficits induced by chronic cerebral hypoperfusion in rats [38]. The present study demonstrated that the combined extract has potential to suppress AChE activity which could relate the improving cognitive and learning and memory function. In addition, 2,3-Butanediol which was found in the combined extract contributed on phytohormone and antioxidant responses [39]. The phytohormone significantly downregulated lipid accumulation [40]. The current results suggested the extract could inhibit the lipase activity leading decreased lipid metabolism which intern reduces the absorption of dietary fat.

However, in order to be used in pharmacological aspects and the way interacts with human system needs to be further explored to recommend its safe, effective possible mechanism and widespread use of in medicine. Therefore, the further study including toxicity and in vivo study will be evaluated to confirm its effect.

\section{CONCLUSION}

The study suggested that synergistic effect of the combined extract which contained Celery and Chinese kale has more capability than using extract alone. The GC-MS study showed chemical compounds that reputed on various bioactive activity. The present bioactive compounds served as antioxidant activity leading to effectively reduce lipase enzyme and AChE neurotransmitter or might be directly affected of phytochemical compound on health benefits. Therefore, the synergistic effect could affect multitargets that contributing on both beneficial effects of metabolic syndrome and cognitive impairment. However, the possible underlying mechanisms will explore in animal model. In addition to assure the consumption safety of novel food, the toxicity will also be investigated.

\section{ACKNOWLEDGMENT}

This work was supported by Science and Technology Institute, Chiang Mai University, Thailand 52000

\section{REFERENCES}

1. Aanchal W, Amit KG, Vatsala S (2019) Role of bioactive compounds in human health. Acta Scientific Medical Sciences 3(9): 25-33.

2. González S (2020) Dietary bioactive compounds and human health and disease. Nutrients 12(2): 348.

3. Rana MK (2014) Herbaceous plants as natural protective food (Functional food (Nutraceuticals). Scientific publisher, Jodhpur, India, pp. 94-103.

4. Ayesha K, Haq N, JiheneBG, Rafia R, Farwa N (2015) Value added products, chemical constituents and medicinal uses of celery (Apium graveolens L.)- A Review. IJCBS 8: 40-48.

5. Praveen N, Ateeque A, Sun-Jin K, Ill-Min C (2012) Chemical composition, antioxidant activity and larvicidal effects of essential oil from leaves of Apium graveolens. Immunopharmacol Immunotoxicol 34(2): 205-209.

6. Sameh B, Ibtissem B, Mahmoud A, Boukef K, Boughattas KA (2011) Antioxidant activity of apium graveolens extracts. JBAPN 1(5-6): 340343.

7. Rożek E, Nurzyńska-Wierdak R, Sałata A, Gumiela P (2016) The chemical composition of the essential oil of leaf celery (Apium graveolens L. var. secalinum alef.) under the plants' irrigation and harvesting method. Acta Sci Pol Hortorum Cultus 15(1): 147-157.

8. Kelm MA, Nair MG (2002) Antioxidant, cyclooxygenase and topoisomerase inhibitory compounds from Apium graveolens Linn. seeds. Phytomedicine 9(4): 312-318.

9. Sima N, Naser A, Gholamreza A (2010) Antinociceptive and antiinflammatory effects of hydroalchoholic extract of Anethum graveolens L. seed. J Med Plants 9(34): 124-130.

10. Abellán Á, Domínguez-Perles R, Moreno DA, García-Viguera C (2019) Sorting out the value of cruciferous sprouts as sources of bioactive compounds for nutrition and health. Nutrients 11(2): E429.

11. Wang YQ Hu LP, Liu GM, Zhang DS, He HJ (2017) Evaluation of the nutritional quality of Chinese kale (Brassica alboglabra Bailey) using 
UHPLC-Quadrupole-Orbitrap MS/MS-based metabolomics. Molecules 22(8): 1262 .

12. Sun B, Yan H, Zhang F, Wang Q (2012) Effects of plant hormones on main health-promoting compounds and antioxidant capacity of Chinese kale. Food Res Int 48: 359-366.

13. Luang-In V, Saengha W, Buranrat B, Chantiratikul A, Ma NL (2020) Cytotoxicity of Selenium-Enriched Chinese Kale (Brassica oleracea var. alboglabra L.) Seedlings Against Caco-2, MCF-7, and HepG2 Cancer Cells. Pharmacog J 12(4): 674-681.

14. Cartea ME, Francisco M, Soengas P, Velasco P (2010) Phenolic compounds in Brassica vegetables. Molecules 16(1): 251-280.

15. Spinella M (2002) The importance of pharmacological synergy in psychoactive herbal medicines. Altern Med Rev 7(2): 130-137.

16. James DA, Rubin W, Jun Y, Eric JL (2006) Preclinical and clinical examinations of Salvia miltiorrhiza and its tanshinones in ischemic conditions. Chinese Medicine 1(3): 1-15.

17. Maurizio F, Jonathan A, Andrew AN, David M, Michael WO, et al. (2005) A double-blind, randomized trial of St John's wort, fluoxetine, and placebo in major depressive disorder. J Clin Psychopharmacol 25(5): 441-447.

18. Rao MR, Anisha G (2018) Preliminary phytochemical and GC MS study of one medicinal plant Carissa spinarum. Indo Am J Pharm Res 8: 414-421.

19. Kaur C, Kapoor HC (2002) Antioxidant activity and total phenolic content of some Asian vegetables. Int J Food Sci Technol 37: 153-161.

20. Chang CC, Yang MH, Wen HM, Chern JC (2002) Estimation of total flavonoid content in propolis by two complementary colorimetric methods. J Food Drug Anal 10: 178-182.

21. Benzie IFF, Strain JJ (1996) The ferric reducing ability of plasma (FRAP) as a measure of "antioxidant power": the FRAP assay. Anal Biochem 239: 70-76.

22. Re R, Pellegrini N, Proteggente A, Pannala A, Yang M, et al. (1999) Antioxidant activity applying an improved ABTS radical cation decolorization assay. Free Radic Biol Med 26: 1231-1237.

23. Ingkaninan $\mathrm{K}$, Temkitthawon $\mathrm{P}$, Chuenchon $\mathrm{K}$, Yuyaem $\mathrm{T}$, Thongnoi $\mathrm{W}$ (2003) Screening for acetylcholinesterase inhibitory activity in plants used in Thai traditional rejuvenating and neurotonic remedies. J Ethnopharmacol 89: 261-264.

24. McDougall GJ, Kulkarni NN, Stewart D (2009) Berry polyphenols in- hibit pancreatic lipase activity in vitro. Food Chem 115: 193-199.

25. Gandhi S, Abramov AY (2012) Mechanism of oxidative stress in neurodegeneration. oxid Med Cell Longev 2012: 428010.

26. Uttara B, Singh AV, Zanboni P, Mahajan RT (2009) Oxidative stress and neurodegenerative diseases: a review of upstream and downstream antioxidant therapeutic options. Curr Neuropharmacol 7(1): 65-74.
27. Pari L, KarthiKesan K (2007) Protective role of caffeic acid against alcohol-induced biochemical changes in rats. Fundam Clin Pharmacol 21(4): 355-361.

28. Palachai N, Wattanathorn J, Muchimapura S, Thukham-mee W (2019) Antimetabolic syndrome effect of phytosome containing the combined extracts of mulberry and ginger in an animal model of metabolic syndrome. Oxid Med Cell Longev 2019: 5972575.

29. Parasuraman S, Thing GS, Dhanaraj SA (2014) Polyherbal formulation: Concept of ayurveda. Pharmacogn Rev 8: 73-83.

30. Srivastava S, Lal VK, Pant KK (2012) Polyherbal formulations based on Indian medicinal plants as antidiabetic phytotherapeutics. Phytopharmacology 2: 1-15.

31. Yuan H, Ma Q, Cui H, Liu G, Zhao X, et al. (2017) How can synergism of traditional medicines benefit from network pharmacology? Molecules 22(7): 1135-1164.

32. Kui L, Miao L, Shuang W (2019) The bioprotective effects of polyphenols on metabolic syndrome against oxidative stress: Evidence and perspectives. Oxid Med Cell Longev 2019: 6713194.

33. Del Rio A, Rodriguez-Mateos D, Spencer JPE, Tognolini M, Borges G, et al. (2013) Dietary (poly)phenolics in human health: structures, bioavailability, and evidence of protective effects against chronic diseases. Antioxid Redox Signal 18(14): 1818-1892.

34. Yoshikawa M, Shimoda H, Nishida N, Takada M, Matsuda H (2002) Salacia reticulata and its polyphenolic constituents with lipase inhibitory and lipolytic activities have mild antiobesity effects in rats. J Nutr 132: 18191824.

35. Buchholz T, Melzig MF (2015) Polyphenolic compounds as pancreatic lipase inhibitors. Planta Med 81: 771-783.

36. lkay O, Murat K, Fatma T, Bilge S (2007) Screening of various phenolic acids and flavonoid derivativesfor their anticholinesterase potential. Zeitschrift fur Naturforschung 62(11-12): 829-832.

37. Gloerich J, van den Brink DM, Ruiter JPN, Naomi van V (2007) Metabolism of phytol to phytanic acid in the mouse, and the role of PPAR $\gamma$ in its regulation. J Lipid Res 48(1): 77-85.

38. Guimarães AG, Oliveira GF, Melo MS, Sócrates CHC, Angelo RA, et al (2010) Bioassay-guided evaluation of antioxidant and antinociceptive activities of carvacrol. Basic Clin Pharmacol Toxicol 107(6): 949-957.

39. Shi Y, Liu X, Fang Y, Tian Q, Jiang H, et al. (2018) 2, 3-Butanediol activated disease-resistance of creeping bentgrass by inducing phytohormone and antioxidant responses. Plant Physiol Biochem 129: 244-250.

40. Ahmad B, Friar EP, Vohra MS, Garrett MD, Serpell CJ, et al. (2020) Mechanisms of action for the anti-obesogenic activities of phytochemicals. Phytochemistry 180: 1-21. 